\title{
Relationship between respiratory symptoms and cough receptor sensitivity
}

\author{
M F Riordan, C S Beardsmore, A M Brooke, H Simpson
}

\begin{abstract}
The relationship was studied between preschool and current respiratory symptoms and cough receptor sensitivity in children. Forty six white children aged 7 years were investigated. They were divided into three groups: (i) healthy children; (ii) children with a history of idiopathic cough; and (iii) children with a history of wheezing.

Cough receptor sensitivity was assessed by the inhalation of serially increasing concentrations of nebulised citric acid. The concentration which first induced a cough was the cough threshold and was taken as a measure of cough receptor sensitivity.

The cough threshold was unrelated to respiratory symptoms, bronchial responsiveness, parental smoking, and atopic status. A wide variation in cough threshold was seen.

Although these results suggest that idiopathic cough is unrelated to cough receptor sensitivity as assessed by the citric acid cough threshold, it is unclear whether threshold measurements are an accurate reflection of receptor sensitivity. (Arch Dis Child 1994; 70: 299-304)
\end{abstract}

The cough reflex is primarily a protective reflex, the aim of which is to prevent the aspiration of foreign particles into the respiratory tract. In addition, cough promotes the clearance of excess secretions from the airways. Non-productive cough is common in children and is often attributed to viral upper respiratory tract infection (URTI). ${ }^{1}$ Cough is also a common symptom of asthma, and may indeed be the only symptom in adults ${ }^{2}$ and children. ${ }^{3}$ The mechanisms underlying nonproductive cough are uncertain but it has been suggested that some patients have hypersensitive cough receptors. ${ }^{4}$ A greater understanding of the mechanism underlying non-productive cough may allow the identification of aetiological factors and define approaches to treatment.

The sensitivity of cough receptors can be studied indirectly using the inhalation of various concentrations of tussive aerosols. The concentration of aerosol which induces cough is taken as a measure of cough receptor sensitivity. Such cough challenge tests have been performed extensively on adult subjects. Conditions which have been shown to be associated with a decrease in cough threshold include viral URTI, ${ }^{5}$ chronic bronchitis, ${ }^{6}$ and bronchiectasis coupled with infection.?
Occasional smoking is associated with an increase in cough threshold. ${ }^{8}$ In 1987 Okayama et al showed a reduced cough threshold in subjects with asthma compared with healthy controls. ${ }^{9}$ This finding was in contrast to other studies, however. ${ }^{6}{ }^{10-12}$ The only previously reported study which included children compared the acetic acid cough thresholds of three groups: a control group, a group reporting cough, and a group of children with asthma. ${ }^{4}$ Differences in cough threshold between the groups were not significant, though a subgroup of subjects with asthma showed a reduction in cough threshold. The validity of comparisons between the groups in this study is questionable, however, as they were not adequately matched for age or sex, and the group reporting cough was not clinically homogeneous.

Previous studies using cough challenge tests have used a variety of different substances to induce cough, a range of protocols for their administration, and a number of different endpoints. There is therefore no standardised method for assessing cough receptor sensitivity. Adult cough challenge tests, though using simple and inexpensive equipment to perform tests, have used protocols which require too much cooperation to be used successfully with children. The only previously reported study including children relied on the use of an astrograph, which is an expensive piece of equipment designed to automatically deliver a series of nebulised solutions. ${ }^{4}$

The aims of this study were (1) to develop a cough challenge test suitable for use in children using simple and inexpensive equipment and (2) to investigate cough receptor sensitivity in relation to past or present symptoms of cough or wheeze in children aged 7 years.

\section{Subjects and methods}

SUBJECTS

Subjects were selected from a large cohort of white children who had originally been recruited at random at the age of 5 years into an ongoing epidemiological study. ${ }^{13}$ The incidence of respiratory symptoms during their preschool years had been established by postal questionnaire. Three groups were identified: (i) healthy children; (ii) children with a history of cough unrelated to URTI; and (iii) children with a history of wheezing. The latter two groups were classified on the basis of parental answers to the questions 'Has your child ever had an attack of wheezing?', 'Does your child usually have a cough without a cold?', and 'Has your child been woken at night by an 
attack of coughing in the previous year?'. ${ }^{13}$ Questions relating to wheeze were preceded by a definition or wheezing.

Subgroups of this cohort were studied again at the age of 7 years when bronchial responsiveness was assessed using a methacholine challenge test. Atopic status was established by skin prick testing to four common allergens (cat, dog, house dust mite, and grass pollen). At this time some parents and children were asked to participate in an additional programme of cough challenge testing. Subjects were recruited on the basis of their original preschool symptoms.

The study group contained 18 boys and 28 girls, with a mean age of $7 \cdot 34$ years (range 6.32-7.99). When these children were recruited into the epidemiological study, two years before the investigation of cough receptor sensitivity, 17 had no respiratory symptoms, 16 were reported to suffer from cough unrelated to URTI, and 13 were reported to suffer from wheeze. None of the children had a history of a severe cardiopulmonary disorder or had ever had a severe lower respiratory tract infection. Of the 13 children reported to have wheeze, 10 had been previously diagnosed as asthmatic by their family doctors.

Six of the children included in the study were receiving drugs for asthma on a regular basis: salbutamol and sodium cromoglycate (three), salbutamol and beclomethasone (two), and salbutamol alone (one). Subjects were asked to stop taking salbutamol and sodium cromoglycate on the night before their tests. Appointments to attend the laboratory for cough challenge testing were postponed if necessary so that testing was performed when the children had been free of URTI for at least three weeks.

\section{COUGH CHALLENGE TEST}

The tussive agent selected for cough challenge testing was citric acid. Crystals of citric acid were dissolved in $0.9 \%$ sodium chloride solution and a range of concentrations increasing in multiples of 1.5 from 5.2 to 675 $\mathrm{mg} / \mathrm{ml}$ were prepared for use on the day of each test. The osmolality of these solutions ranged from a minimum of $250 \mathrm{mosm} / \mathrm{kg}$ up to $>1500 \mathrm{mosm} / \mathrm{kg}$. All of the solutions were strongly acidic with the $\mathrm{pH}$ ranging from 2.5 to $0 \cdot 25$. Citric acid mist was generated using a Wright's nebuliser driven by a cylinder of compressed air. To standardise the output a rotameter (GEC-Elliott Process Instruments Ltd, Croyden) was positioned between the cylinder and the nebuliser and the flow rate adjusted to give a reading of $10 \mathrm{l} /$ minute. The mass median aerodynamic diameter of the aerosol droplets, assessed using a Multi Stage Liquid Impinger (Fisons Pharmaceuticals Ltd, Research and Development Division, Loughborough) was $2.65 \mu \mathrm{m}$ (GSD 1.94).

During each cough challenge the subject breathed the mists generated by the nebuliser for 30 seconds followed by a 30 second rest period. After a sodium chloride control mist, citric acid mists were breathed in increasing order of concentration. The subjects were seated and breathed through a mouthpiece connected to the nebuliser with an opening for air entrainment and expiration. A nose clip was worn during the inhalation of mist. The cough threshold was defined as the concentration of citric acid which first provoked cough, provided that the subsequent concentration also provoked cough.

\section{PROCEDURE}

Children attended the respiratory laboratory between 1 and $5 \mathrm{pm}$ to avoid the potential effects of diurnal variation in the cough response. ${ }^{14} \mathrm{~A}$ questionnaire concentrating on respiratory symptoms in the previous year was completed and the respiratory system of the child examined. Baseline spirometry was performed using a wet spirometer (Gould Godart Pulmonet III) to measure forced vital capacity (FVC), forced expiratory volume in one second $\left(\mathrm{FEV}_{1}\right)$, and maximum midexpiratory flow (MMEF). ${ }^{15}$ Each child then underwent a cough challenge test, during the course of which he or she was distracted with toys or books. Spirometric measurements and examination were repeated after the cough challenge.

In accordance with the Children Act the nature of the tests to be performed was explained to the participating child and to his or her parents. Children were not informed that the induction of cough was the specific aim of the test as it was considered that this might influence the results.

Five children developed URTI in the days after the visit and in these subjects the tests were repeated after a mean interval of nine weeks.

The study protocol was approved by the Leicestershire Health Authority committee on the ethics of clinical investigation.

\section{POWER CALCULATION}

Accurate power calculations in advance of this study were not possible as the standard deviation of the measurement in the normal population, which is necessary for the calculation, was unknown. Using data from an adult study which used a protocol similar to that employed here, ${ }^{9}$ however, and assuming that the variability in children was the same as in adults, we calculated that the power of the study to detect a significant difference in cough threshold between the groups was in excess of $90 \%$.

\section{ANALYSIS}

Citric acid cough threshold values were analysed in relation to preschool respiratory symptoms at the time of the original epidemiological study, and current respiratory symptoms.

Threshold values of the members of the various symptom groups were compared before logarithmic transformation by a 
non-parametric Kruskal-Wallis test, and after appropriate transformation by a one way analysis of variance.

Cough threshold values were also analysed in relation to parental smoking and atopic status.

\section{Results}

At the time of the investigation 23 children were reported to have had no respiratory symptoms in the previous 12 months, 13 to have had cough, and 10 to have had wheeze. Figure 1 shows the extent to which subjects' reporting of symptoms had changed over the two year period covered by the studies. The group reporting cough showed the greatest propensity to improve.

\section{SPIROMETRY}

Thirty five $(76 \%)$ of the 46 children had the necessary coordination to perform spirometry successfully before and after the cough challenge. In all instances spirometry was normal and changes in FVC, $\mathrm{FEV}_{1}$, or MMEF did not exceed $15 \%$ of baseline value in any child. Mean changes were $-1 \cdot 2 \%$ (FVC), $-2.3 \%\left(\mathrm{FEV}_{1}\right)$, and $0.3 \%$ (MMEF) for the group as a whole. Thus the citric acid cough challenge did not appear to alter airway mechanics.

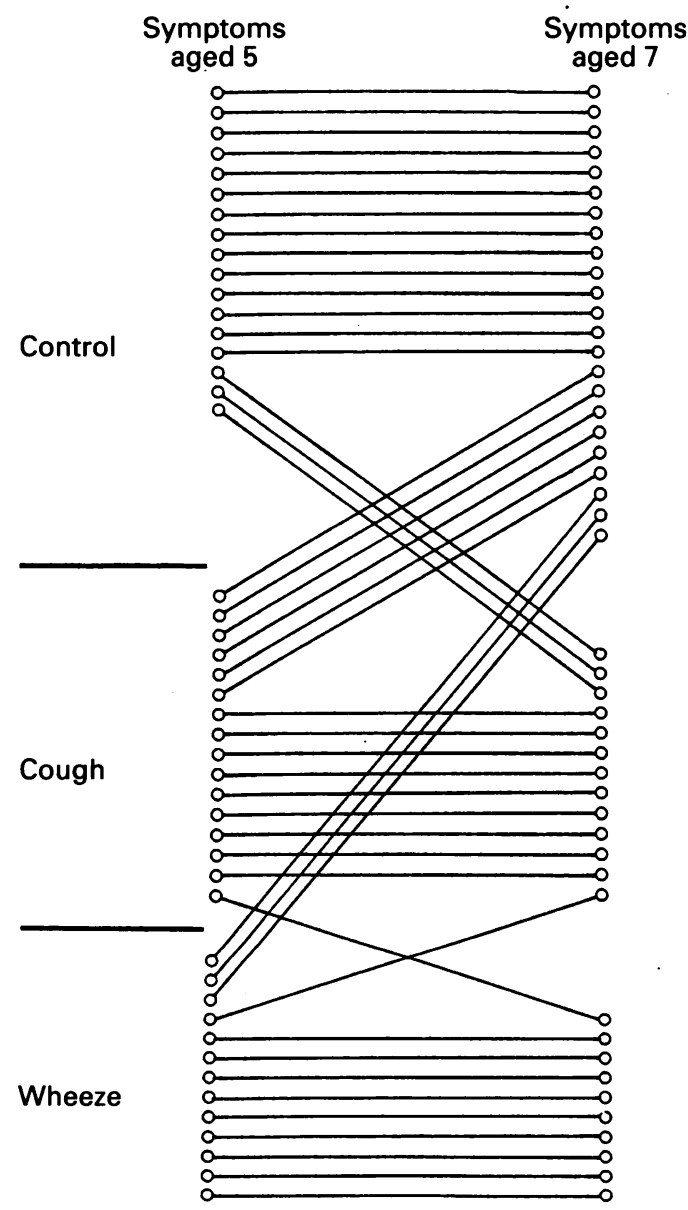

Figure 1 Variation in symptom reporting shown by subjects over the two year period before cough challenge testing.

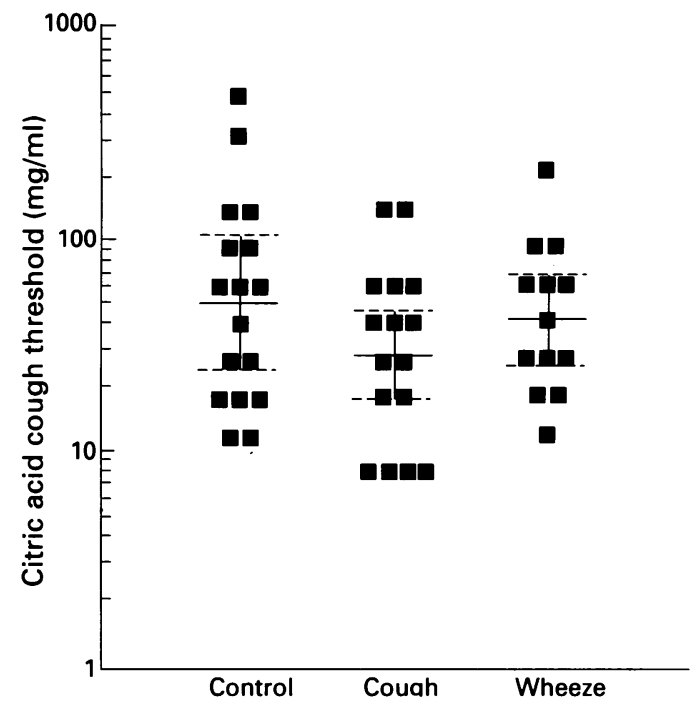

Figure 2 Individual values of citric acid cough threshold in three groups of children. For each group the bars represent the geometric mean and $95 \%$ confidence interval. Symptoms were established at the time of the original epidemiological study, when the children were aged 5 years.

\section{COUGH THRESHOLDS}

All of the 46 children successfully completed the cough challenge test, which proved to be entirely acceptable to them and their parents. There was a wide range of cough thresholds within the group; cough was induced in some children at $7.8 \mathrm{mg} / \mathrm{ml}$ whereas others only coughed at $450 \mathrm{mg} / \mathrm{ml}$. In all three groups of children the cough threshold values appeared to have a log normal distribution (figs 2 and 3).

When the children were divided into three groups according to symptoms reported at age 5 years there was no difference in cough threshold according to group (fig 2). When the children were grouped according to current respiratory symptoms no difference in cough threshold to inhaled citric acid was observed (fig 3).

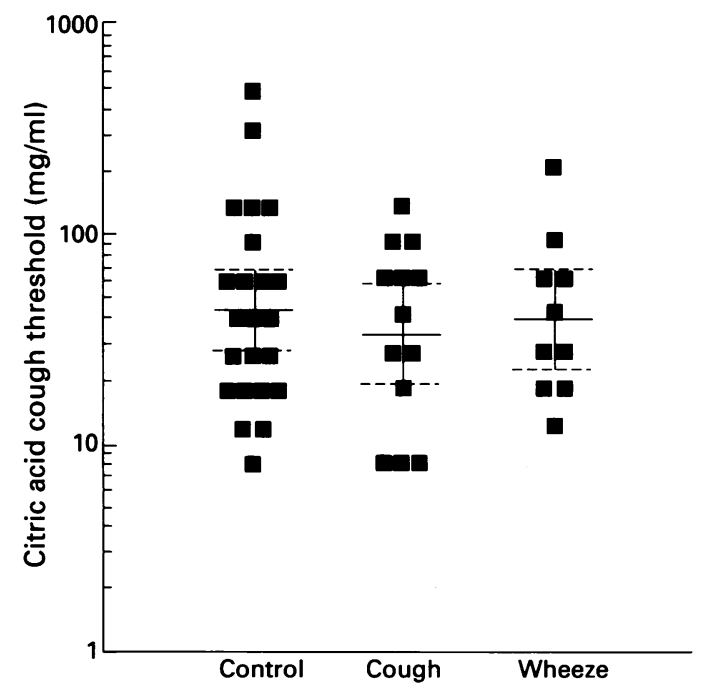

Figure 3 Individual values of citric acid cough threshold in three groups of children. For each group the bars represent the geometric mean and $95 \%$ confidence interval. Symptoms were established at the time of the cough receptor sensitivity study, when the children were aged 7 years. 


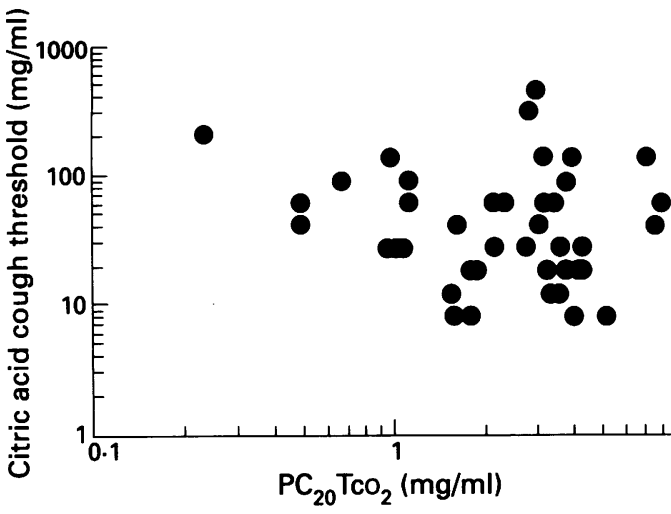

Figure 4 Citric acid cough threshold plotted against $P C_{20}$ $\mathrm{TCO}_{2}$ of methacholine for 41 children. Methacholine threshold values were unavailable for five members of the study group.

INFLUENCE OF RESPIRATORY SYMPTOMS ON COUGH THRESHOLD

Four children were noted to be coughing and two more were wheezing on auscultation before testing. Although most parents complied with the request to postpone tests if children had current or recent URTI, three of these symptomatic children were felt to be developing URTI at the time of their visits to the laboratory. Two children who had been asymptomatic in the weeks preceding the test and who had appeared well at the time of the visit developed symptoms compatible with a viral URTI in the next week. The exclusion of any, or all, of these children from the final analysis of cough threshold values had no significant effect and all their results were included.

Tests were repeated on all five subjects thought to have been studied initially during the prodrome of a viral illness. The repeat tests were performed about nine weeks after the initial testing. The cough threshold was higher on repeat testing in four subjects and slightly lower in the fifth. Substituting the repeat results into the statistical analysis did not alter the outcome.

ASSOCIATION BETWEEN COUGH THRESHOLD AND BRONCHIAL RESPONSIVENESS, ATOPIC STATUS, OR SMOKING IN THE HOME Bronchial responsiveness to inhaled methacholine has been assessed as part of the ongoing epidemiological study. The concentration of methacholine which induced a $20 \%$ decrease in transcutaneous oxygen $\left(\mathbf{P C}_{20}\right.$ $\left.\mathrm{TCO}_{2}\right)$ was known for $41(89 \%)$ children and was taken as a measure of bronchial reactivity. There was no correlation between cough threshold and bronchial reactivity to inhaled methacholine (fig 4).

Atopic status had been assessed as part of the ongoing epidemiological study by skin prick testing $37(80 \%)$ children. Nine (24\%) had shown a positive response to one or more common allergen, but their cough threshold did not appear to be different from that of the non-atopic children (fig 5).

Eighteen (39\%) children came from nonsmoking households and 27 (59\%) from homes where at least one parent smoked;

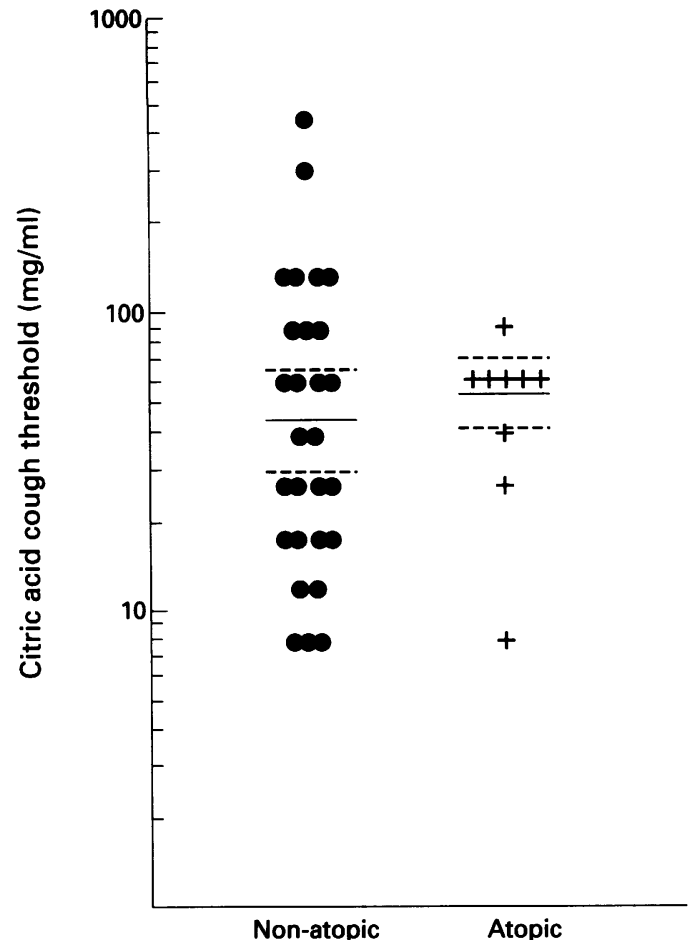

Figure 5 Citric acid cough thresholds of atopic and nonatopic subjects. Bars represent the geometric mean threshold and $95 \%$ confidence interval.

information was not available on one child. There was no difference in citric acid cough threshold of children from smoking $v$ nonsmoking households (fig 6).

\section{Discussion}

DEVELOPMENT OF THE COUGH CHALLENGE TEST Previous studies have used a variety of different substances to induce cough. These include

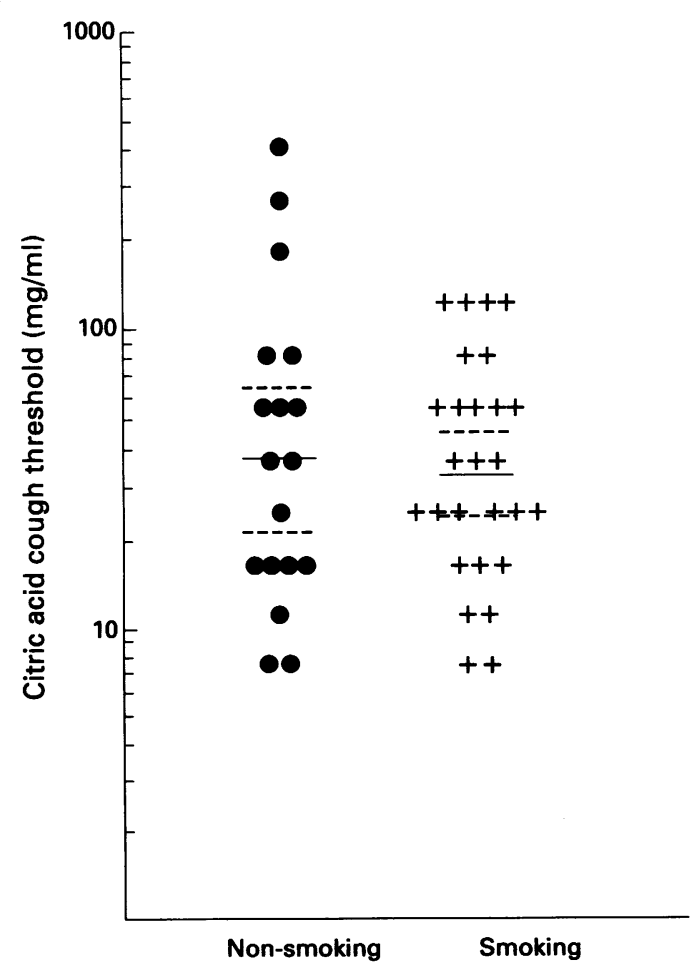

Figure 6 Citric acid cough thresholds of subjects in smoking and non-smoking families. Bars represent the geometric mean threshold and $95 \%$ confidence interval. Data were unavailable for one subject. 
aerosols of ammonia or ether, ${ }^{16}$ capsaicin, ${ }^{17}$ and acetic acid. ${ }^{4}$ In this study citric acid was selected as the tussive agent because it has been widely used in previous studies of cough, ${ }^{101118}$ is cheap, non-toxic, and has a short duration of action. It dissolves readily in water and produces a reproducible concentration-response relationship in adults. ${ }^{18}$ It occurs naturally in citrus fruit and is widely used in the food industry as a flavouring and preservative, and is therefore acceptable to children and their parents.

The Wright's nebuliser was chosen to generate the mist as it has been widely used for challenge procedures and a large percentage of its output is in droplets of respirable size that is, $<5 \mu \mathrm{m}$ in diameter. Previous cough challenge tests have used the inhalation of nebulised solutions either as a single large breath ${ }^{11} 19$ or during tidal breathing. ${ }^{49}$ The single breath technique requires a greater degree of subject cooperation and a tidal breathing technique was therefore adopted for this study.

In some studies different concentrations of tussive agent have been inhaled in random order, ${ }^{1011}$ whereas in others increasing concentrations have been presented. 491218 Young children may not be willing or able to continue with a study once they have started to cough. Therefore, after an initial control solution of $0.9 \%$ sodium chloride, citric acid mists were used in increasing concentrations.

The 'cough threshold' was taken as the concentration which provoked the first cough either during the inhalation or subsequent 30 second rest period, provided that the next inhalation of citric acid also provoked cough. ${ }^{20}$ It was hoped that this would avoid coughing unrelated to the challenge test being recorded as the threshold. The cough challenge test ended when the subject had coughed in response to two consecutive inhalations of citric acid.

The cough challenge test developed for this study was entirely acceptable to all children and their parents. In many instances siblings who accompanied the index child expressed a desire to participate in testing, and several parents spontaneously volunteered to return for additional testing if required.

\section{COUGH THRESHOLD}

The study found no relationship between cough threshold to inhaled citric acid and either preschool or current respiratory symptoms in the children studied. A wide variation in the citric acid cough thresholds of children within each of the study groups was observed.

The variability in this study was greater than that observed in a previous study using similar methodology. ${ }^{9}$ Therefore the power of our study to detect a difference of $30 \mathrm{mg} / \mathrm{ml}$ in cough threshold was reduced to $21 \%$ (calculations based on untransformed data) or $45 \%$ (calculations performed after logarithmic transformation). The power of the study to detect a difference between groups equivalent to $2 \times 1.5$ dose increments was $64 \%$, and to detect a difference of two doubling doses was $97 \%$.
When the three groups of children were compared, regardless of whether the grouping was based on symptoms at the time of cough challenge testing or at the time of initial recruitment two years previously, the cough threshold was lowest in the children with coughs and highest in the normal controls. Although this difference did not approach statistical significance, it was calculated that we would need to study over 650 children for the difference to become significant at the 5\% level, with a power of $80 \%$.

It has been suggested that cough in some patients is due to an underlying hypersensitivity of their cough receptors. ${ }^{4}$ The reasons for this are uncertain, but it may be that the hypersensitivity is due to the action of local inflammatory mediators. Cough receptors could work rather like pain receptors, where local inflammatory mediators increase receptor sensitivity by altering the ionic permeability of the membrane, thereby increasing the resting potential of the cells. ${ }^{21}$ Although this is a possibility, other factors may be playing an important part in the determination of the cough threshold of an individual. These could include individual variations in the central control of the cough reflex and adoption of different respiratory patterns during the inhalation of tussive stimuli. Banner et al have shown significant differences in ventilatory response to inhaled carbon dioxide between adult subjects with 'high' and 'low' cough thresholds. ${ }^{20}$ Differences in the central regulation of cough may account for the wide spread of cough thresholds seen in our study group. This requires further study.

Two studies have shown that lower inspiratory flow rates are associated with significantly lower cough thresholds in response to aerosols of capsaicin ${ }^{22}$ and citric acid. ${ }^{19}$ This effect was attributed to an increase in the laryngeal deposition of citric acid and capsaicin at lower inspiratory flow rates. Hansson et al confirmed a lower cough threshold at low inspiratory flow rates, but their drug deposition studies indicated that a low flow rate increased peripheral deposition of capsaicin. ${ }^{23}$ In all three experiments large single breath inhalations of tussive agents were used. The effect of variations in inspiratory flow rate during tidal breathing on cough threshold has yet to be extensively studied, but in a small pilot study on six adult volunteers we have shown that although the adoption of patterns of hyperventilation and hypoventilation produced significant changes in inspiratory flow rate and minute ventilation, they had no significant effect on cough threshold (unpublished work). It thus seems unlikely that the variation in cough receptor sensitivity observed in the children could be attributed to different respiratory patterns.

RELATIONSHIP BETWEEN COUGH THRESHOLD AND BRONCHIAL RESPONSIVENESS, ATOPIC STATUS, OR SMOKING IN THE HOME

In this study there was no correlation between citric acid cough threshold and bronchial 
reactivity as measured by methacholine challenge. This observation supports the hypothesis that cough and bronchoconstriction are separate airway reflexes and is consistent with the findings of a number of other studies. 91218

It has been shown that a group of patients with asthma with a low cough threshold to inhaled acetic acid was significantly less atopic than another group of patients with asthma with a high cough threshold. ${ }^{4}$ The two groups differed significantly in terms of age, however. In this study there was no relationship between cough threshold and atopy, where atopy was defined as a positive response to at least one common antigen on skin prick testing.

Measurements of cough threshold were made about four months after the determination of bronchial reactivity and atopic status. The long term repeatability of cough challenge testing is unknown and further investigation of possible relationships between the cough receptor sensitivity and atopy and bronchial responsiveness would be worthwhile.

An association between parental smoking and the reporting of a variety of respiratory symptoms, including cough and wheeze, has been shown. ${ }^{24}$ This study did not find a relationship between cough threshold and either parental smoking or a history of cough. This may be a reflection of the fact that the size of the study did not allow analysis to take into account variable exposure within the smoking group, though the data obtained show a large degree of overlap (fig 6).

The variable results of studies using cough challenge testing have led us to question the assumption that citric acid cough threshold is an accurate reflection of cough receptor sensitivity. The results of our study indicate that there is no clear relationship between cough threshold and the reporting of idiopathic cough in children. The significance of these findings is uncertain: the results suggest that either (1) idiopathic cough is unrelated to cough receptor sensitivity, or (2) cough threshold is not a measure of cough receptor sensitivity. Factors other than cough receptor sensitivity may affect cough threshold, including differences in the central control of cough reflex and the way in which the tussive agent is inhaled (tidal breathing or single vital capacity inspiration). The contribution that differences in cough receptor sensitivity make to cough threshold may be masked by the effects of these and other variables. An accurate comparison of cough receptor sensitivity will only be possible once the effects of these confounding variables have been more fully elucidated.

M F Riordan was in receipt of a Wolfson Foundation Intercalated Award. A M Brooke was supported by the National Asthma Campaign.

1 Eigen $\mathrm{H}$. The clinical evaluation of chronic cough. Pediatr Clin North Am 1982; 29: 67-78.

2 McFadden ER. Exertional dyspnea and cough as preludes to acute attacks of bronchial asthma. N Engl f Med 1975; 292: 555-9.

3 Cloutier MM, Loughlin GM. Chronic cough in children: a manifestation of airway hyperreactivity. Pediatrics 1981; 67: 6-12.

4 Mitsuhashi M, Mochizuki H, Tokuyama K, Morikawa A, Kuroume T. Hyperresponsiveness of cough receptors in patients with asthma. Pediatrics 1985; 75: 855-8.

5 Empey DW, Laitinen LA, Jacobs L, Gold MW, Nadel JA. Mechanisms of bronchial hyperreactivity in normal subjects after upper respiratory tract infection. Am Rev Respir Dis 1976; 113: 131-9.

6 Fujimura M, Sakamoto S, Kamio Y, Matsuda T. Cough threshold to tartaric acid and bronchial responsiveness to methacholine in patients with asthma and sino-bronchial methacholine in patients with asthma and

7 Choudry NB, Fuller RW. Sensitivity of the cough reflex in patients with chronic cough. Eur Respir $\mathcal{f} 1992$; 5: 296-300.

8 Vlastos FD, Dessanges JF, Lockhart A, Pretet S. Cough and bronchoconstriction induced by citric acid in smokers, occasional smokers and non-smokers. Rev Mal Respir 1991; 8: 397-401.

9 Okayama M, Katsumata U, Biana RT, et al. Dose related cough response to citric acid and relationship to airway reactivity [Abstract]. Am Rev Respir Dis 1987; 135 (suppl): A321.

10 Bickerman HA, Barach AB, Itkin S, Drimmer F. The experimental production of cough in human subjects induced by citric acid aerosols: preliminary studies on the induced by citric acid aerosols: preliminary studies on the evaluation

11 Poundsford JC, Birch MJ, Saunders KB. Effect of bronchodilators on the cough response to inhaled citric acid in normal and athmatic subjects. Thorax 1985; 40: 662-7.

12 Fujimura M, Sakamoto S, Kamio Y, Matsuda T. Cough receptor sensitivity and bronchial responsiveness in normal and asthmatic subjects. Eur Respir $\mathcal{f}$ 1992; 5: 291-5.

13 Luyt DK, Burton PR, Simpson H. Epidemiological study of wheeze, doctor-diagnosed asthma and cough in preschool children in Leicestershire. BMF 1993; 306: 1386-9.

14 Poundsford JC, Saunders KB. Diurnal variations and adaptation of the cough response to citric acid in normal subjects. Thorax 1985; 40: 657-61.

15 ATS Guidelines. Standardization of spirometry. Am Rev Respir Dis 1987; 136: 1285-98.

16 Hills BR. The assessment of cough suppressing drugs. Lancet 1952; i: 1230-5.

17 Collier JG, Fuller RW. Capsaicin inhalation in man and the effects of sodium cromoglycate. Br $\mathcal{Y}$ Pharmacol 1984; 81: 113-7.

18 Auffarth B, de Monchy JGR, van der Mark TW, Postma DS, Koeter GH. Citric acid cough threshold and airway DS, Koeter GH. Citric acid cough threshold and airway responsiveness in asthmatic patients and smokers with
chronic airflow obstruction. Thorax 1991; 46: 638-42.

19 Barros MJ, Zammattio SJ, Rees PJ. Importance of inspiratory flow rate in the cough response to citric acid inhalation in normal subjects. Clin Sci 1990; 78: 521-5.

20 Banner AS, Drummer A. Relationship between citric acid cough threshold and ventilatory response to $\mathrm{CO}_{2}$ in normal subjects [Abstract]. Am Rev Respir Dis 1987; 135 (suppl): A489.

21 Melzack $R$ Wall PD. The challenge of pain. Rev Ed. Harmondsworth: Penguin Books, 1982

22 Barros MJ, Zammattio SJ, Rees PJ. Effect of changes in inspiratory flow rates on cough responses to inhaled inspiratory flow rates on cough respo
capsaicin. Clin Sci 1991; 81: 539-42.

23 Hansson L, Wollmer P, Dahlback M, Karlsson J-A Regional sensitivity of human airways to capsaicininduced cough. Am Rev Respir Dis 1992; 145: 1191-5.

24 Charlton A. Children's coughs related to parental smoking. BMF 1984; 288: 1647-9. 